\section{Antegrade intravenous catheterization for metabolic studies in man}

To the Editor: Glucose or insulin clamp studies are clinical research procedures aimed at a comprehensive understanding of in vivo insulin and glucose and substrate metabolism in humans. These clinical research studies often involve separate infusions of either insulin or glucose under a controlled administration protocol, and sampling of blood to assess the physiologic response to the agent administered. It is preferable to sample blood from the arterial compartment because venous data, though easier to obtain, represents the metabolism of the substrate in the particular organ drained by the capillary and venous bed. The fraction of metabolite, such as glucose, extracted by the organ is dependent on the venous bed being sampled. For these reasons, early studies used the placement of an arterial catheter for blood sampling when evaluating substrate metabolism [1]. In addition, when assessing a rapid response to a sudden change in physiological stimulus, venous sampling is inadequate due to the increased transit time and delayed ability to measure a response. However, arterial sampling imparts small risk to tissues distal to the arterial sampling catheter [2, 3]. To minimize subject risk while maintaining the integrity of the substrate measurement, many researchers use a technique to "arterialize" venous blood. For this technique, a catheter is placed in a dorsal hand vein, in a retrograde manner, to the most distal site from which adequate sampling is possible and the hand is placed in a box heated to $65-70^{\circ} \mathrm{C}$ [4]. This manoeuvre causes vasodilation in the hand and as the resting hand extracts little substrate an arteriovenous shunt is produced.

The use of the retrograde catheter has become common practice throughout studies of human physiology. However, in comparison to the placement of the antegrade catheter, placement in the retrograde fashion requires some practice and is more difficult to carry out. We hypothesized that arterialized blood could be collected with an intravenous catheter placed in an antegrade manner.

We evaluated 11 consecutive obese adolescent subjects who were participating in a study to evaluate dietary induced weight loss. The experimental protocol was approved by the Human Subject Committee at Children's Hospital, Boston,
Massachusetts, USA and informed assent and consent were obtained from all participants and their parents. All subjects were free of endocrine and major active cardiovascular, pulmonary, renal, or hepatic diseases. Catheters were placed antegrade (tip towards the heart) in a distal hand vein. The catheterized hand was placed in a box heated to $65^{\circ} \mathrm{C}$ and allowed to rest for 20-30 min prior to the start of sampling. Blood was drawn in a heparinized syringe, and put on ice before laboratory analysis of $\mathrm{pH}, \mathrm{PO}_{2}, \mathrm{O}_{2}$ saturation, $\mathrm{PCO}_{2}$, and bicarbonate, analysed using the 800 Blood Gas System (Bayer Corporation, Diagnostics Division, Norwood, Mass., USA) based on ion specific electrochemistry. All data are expressed as means \pm SD unless otherwise noted.

Demographic and clinical characteristics of the subjects were: age, $15.7 \pm 2.1$ years old; male/female, $1 / 10$; body mass index, $36.3 \pm 4.0 \mathrm{~kg} / \mathrm{m}^{2}$; fasting blood glucose, $14.62 \pm 1.69 \mathrm{mmol} / \mathrm{l}$. Individual laboratory results of blood gas analysis are shown in Table 1. The mean $\mathrm{pH}(7.41 \pm 0.02), \mathrm{PO}_{2}(12.20 \pm 2.25 \mathrm{kPa}), \mathrm{O}_{2}$ saturation $(96.7 \pm 1.3 \%), \mathrm{PCO}_{2}(5.48 \pm 0.23 \mathrm{kPa})$, and bicarbonate $(25.5 \pm 1.4 \mathrm{mmol} / \mathrm{l})$ were within the normative range for arterial samples.

The results of this investigation show that arterialized blood can be obtained with antegrade catheter placement in a distal hand vein. The antegrade technique is simpler and does not require additional training procedures for reliable placement. Easier procedures yield higher rates of catheter placement with lower rates of unsuccessful attempts, thereby increasing subject comfort without compromising the acquisition or quality of research data. Based on a Medline database search, there are more than 1000 references in the literature referring to euglycaemic and hyperglycaemic clamp procedures in humans and almost 600 citations, as current as this year [4] for retrograde catheter placement, showing the frequent use of this procedure. In conclusion, antegrade catheter placement, in a distal vein with the hand placed in a heated box, should be considered as an alternative to retrograde catheter placement under similar conditions for physiologic research studies.

Acknowledgements. This study was supported by the General Clinical Research Center (M01 RR02172) at Children's Hospital Boston. The authors thank C. Murphy, RN, BSN.

A. B. Goldfine, C. B. Ebbeling, D. S. Ludwig

Published online: 18 September 2002

(C) Springer-Verlag 2002 
Table 1. Blood gas data

\begin{tabular}{llclll}
\hline Subject & $\mathrm{pH}$ & $\mathrm{PO}_{2}(\mathrm{kPa})$ & $\mathrm{O}_{2} \mathrm{Sat}(\%)$ & $\mathrm{PCO}_{2}(\mathrm{kPa})$ & $\begin{array}{l}\text { Bicarbonate } \\
(\mathrm{mmol} / \mathrm{l})\end{array}$ \\
\hline 1 & & & & 24 \\
2 & 7.40 & 9.38 & 94 & 5.35 & 25 \\
3 & 7.41 & 9.56 & 95 & 5.42 & 25 \\
4 & 7.43 & 14.23 & 98 & 5.16 & 26 \\
5 & 7.42 & 11.70 & 97 & 5.55 & 23 \\
6 & 7.38 & 9.89 & 97 & 5.24 & 26 \\
7 & 7.42 & 12.53 & 97 & 5.48 & 28 \\
8 & 7.41 & 12.42 & 97 & 5.60 & 27 \\
9 & 7.40 & 15.28 & 98 & 6.01 & 26 \\
10 & 7.44 & 15.84 & 98 & 5.45 & 25.5 \\
11 & 7.40 & 10.46 & 96 & 5.53 & 1.4 \\
Mean & 7.41 & 12.89 & 97 & 5.59 & $24-27$ \\
SD & 7.41 & 12.20 & 96.7 & 5.48 & $20-33$ \\
Arterial range & $7.35-7.45$ & $11.33-14.00$ & $94-98$ & $4.67-6.00$ & \\
Venous range & $7.31-7.41$ & $3.40-6.67$ & $80-85$ & $4.67-6.00$ & \\
\hline
\end{tabular}

\section{References}

1. DeFronzo RA, Tobin JD, Andres R (1979) Glucose clamp technique: a method for quantifying insulin secretion and resistance. Am J Physiol 237: E214-E223

2. Hall R (1971) Vascular injuries resulting from arterial puncture of catheterization. Br J Surg 58: 513-516

3. Machleder HI, Sweeney JP, Barker WF (1972) Pulseless arm after brachial-artery catheterisation. Lancet i: 407-409
4. McGuire EA, Helderman JH, Tobin JD, Andres R, Berman M (1976) Effects of arterial versus venous sampling on analysis of glucose kinetics in man. J Appl Physiol 41: 565-573

Corresponding author: Dr. A. B. Goldfine, Joslin Diabetes Center, One Joslin Place, Boston, MA 02215, USA. E-mail: Allison.Goldfine@Joslin.Harvard.Edu 